\title{
The clinical features of Ehlers-Danlos syndrome type VIIB resulting from a base substitution at the splice acceptor site of intron 5 of the COL1A2 gene
}

\author{
A J Carr, A A Chiodo, J M N Hilton, C W Chow, A Hockey, W G Cole
}

Department of Paediatrics, University of Melbourne, Parkville,

Victoria 3052,

Australia

A J Carr

A A Chiodo

W G Cole

New South Wales

Institute of Forensic

Medicine, Glebe, New

South Wales 2037,

Australia

$\mathrm{J} M \mathrm{~N}$ Hilton

Department of Anatomical

Pathology, The Royal

Children's Hospital,

Parkville,

Victoria 3052,

Australia

C W Chow

Department of Genetics, King

Edward Memorial

Hospital for Women,

Subiaco, Western

Australia 6008,

Australia

A Hockey

Correspondence to Professor Cole,

Division of Orthopaedics,

The Hospital for Sick

Children, 555 University

Avenue, Toronto, Ontario

Canada M5G 1 X8.

Received 22 September 1993

Accepted for publication

12 November 1993

\begin{abstract}
The features of a 32 year old woman with Ehlers-Danlos syndrome type VIIB and affected members of her family, resulting from a mutation in one COL1A2 allele, were studied. Her dermal type I collagen contained $\alpha 2(I)$ chains and mutant pN- $\alpha 2$ (I) chains in which the amino-terminal propeptide remained attached to the $\alpha 2(I)$ chain. She was heterozygous for an $\mathbf{A G} \rightarrow \mathbf{A C}$ mutation at the splice acceptor site of intron 5 of the COL1A2 gene. The mutation activated a cryptic AG splice acceptor site corresponding to positions +14 and +15 of exon 6 of the COL1A2 gene. In contrast to previous reports only five, rather than all 18, amino acids encoded by exon 6 were deleted in the proband. The deleted peptide removed the amino-proteinase cleavage site, but not the nearby lysine cross linking site in the amino-telopeptide of the $\alpha 2$ (I) chain.
\end{abstract}

She was born with bilateral hip dislocations, knee subluxations, and generalised joint hypermobility. Bilateral inguinal herniae and an umbilical hernia were present at birth. Facial features included a depressed nasal bridge with prominent paranasal folds. The skin was soft, moderately hyperelastic, and sagged over the face. Skin fragility and easy bruising were apparent from childhood. Skin wounds healed slowly and with broad, paper thin scars. Throughout her life, she had multiple fractures of the small bones of her hands and feet following moderate trauma.

Electron microscopy of the proband's dermis as well as deep fascia and hip joint capsule from her affected brother showed that collagen fibrils in transverse section were nearly circular but with irregular margins. Light microscopy of bone from her affected brother and son showed normal Haversian systems and lamellar bone. All of these tissues contained approximately equal amounts of the normal and mutant $\alpha 2(I)$ chains.

The findings of this study confirm that loss of the amino-proteinase cleavage site of the pro $\alpha 2(I)$ collagen chains, owing to anomalous splicing of exon 6 sequences in the conversion of pre-mRNA to mRNA, produces the clinical features of EhlersDanlos syndrome type VIIB. The history of frequent fractures found in this family is atypical and indicates an overlap with osteogenesis imperfecta.

(F Med Genet 1994;31:306-311)

Type I collagen is the major fibrillar collagen of dermis, ligament, tendon, and bone. It is synthesised as a larger precursor, procollagen, consisting of two pro $\alpha 1(\mathrm{I})$ and one pro $\alpha 2(\mathrm{I})$ chains. During, or shortly after, secretion the $\operatorname{amino}(\mathrm{N})$ - and carboxyl(C)-terminal propeptide extensions of the pro $\alpha$ chains are removed by $\mathrm{N}$ - and $\mathrm{C}$-proteinases, respectively, to yield the mature chains of type I collagen. Genetic defects of the $\mathrm{N}$-proteinase cleavage sites or of the $\mathrm{N}$-proteinase enzyme produce the type VII variant of the Ehlers-Danlos syndrome (EDS).

The main phenotypic features of this variant of EDS are congenital joint dislocations and severe generalised joint hypermobility. ${ }^{1}$ EDS type VIIA results from mutations that remove the N-proteinase cleavage site of the pro $\alpha 1$ (I) chains. EDS type VIIB results from similar defects involving the pro $\alpha 2(\mathrm{I})$ chains. EDS type VIIC results from a deficiency of $\mathrm{N}$ proteinase.

The two reported cases of the VIIA variant were the result of a $G \rightarrow A$ transition at the -1 position of the splice donor site of intron 6 of the pro $\alpha 1(\mathrm{I})$ gene (COL1A1). This mutation results in alternative splicing with products lacking exon 6 encoded sequences, which includes the $\mathrm{N}$-proteinase cleavage site, or including exon 6 sequences and a substitution of methionine-159 by isoleucine. ${ }^{2-4}$ The clinical features of these two cases were similar.

Ten cases of the type VIIB variant have been described; three were the result of $G \rightarrow A$ transition at the -1 position of intron 6 , as in the type VIIA cases, except that they involved the COL1A2 gene. ${ }^{5-7}$ Six cases had point mutations of the GT dinucleotide splice donor site of intron 6 which resulted in the complete loss of exon 6 encoded sequences from the $\alpha 2(1)$ mRNA and chain..$^{8-13}$ The deleted sequence included the $\mathrm{N}$-proteinase cleavage site and the cross linking lysine site in the $\mathrm{N}$ telopeptide of the $\alpha 2(1)$ chain. In the case reported here, there was partial loss of exon 6 encoded sequences owing to a base substitution at the splice acceptor site of intron 5 of the COL1A2 gene which activated a cryptic splice site at positions +14 and +15 of exon $6 .^{14}$ The $\mathrm{N}$-proteinase cleavage site was lost but the 
nearby cross linking lysine site in the $\mathrm{N}$ telopeptide was retained.

Dermatosparaxis (EDS type VIIC) was first recognised as a recessively inherited disorder of cattle and was subsequently described in dogs, cats, and sheep. ${ }^{15-20}$ Two human cases of type VIIC, owing to N-proteinase deficiency with retention of the $\mathrm{N}$-propeptides of pro $\alpha 1(\mathrm{I})$ and pro $\alpha 2(\mathrm{I})$ chains, resemble clinically and histologically the animal equivalent, dermatosparaxis. ${ }^{21} 22$

We report the phenotypic features of EDS type VIIB resulting from the partial loss of exon 6 encoded sequences from the COL1A2 gene. The findings suggest that the retention of the $\mathrm{N}$-propeptide is the main determinant of the phenotype.

\section{Case report}

CLINICAL FEATURES

The proband was the eighth child of unrelated parents (fig 1). She was born at 37 weeks' gestation by normal vaginal delivery and weighed $2500 \mathrm{~g}$. She had bilateral hip dislocations which were treated by splintage and later by serial plaster of Paris casts. Both knees were hyperextended with the tibiae subluxed anteriorly. She also had bilateral inguinal herniae and an umbilical hernia at birth; they were managed without surgery.

Her height was between the 25th and the 50th centiles throughout growth. Walking was delayed until she was 2.5 years old. In early childhood, her generalised ligamentous laxity produced frequent, painful patellar and shoulder dislocations. She was usually able to reduce them herself. By the age of 7 years she was independently mobile. She had learnt to reduce the frequency of joint dislocations and subluxations by avoiding running and other activities. She had mild postural pes planoabducto-valgus deformities of the feet. Her finger joints, particularly the interphalangeal joints, were hypermobile with swan neck deformities. During puberty she developed a mild, non-progressive thoracolumbar scoliosis measuring $25^{\circ}$.

She had frequent fractures throughout childhood, particularly of the small bones of

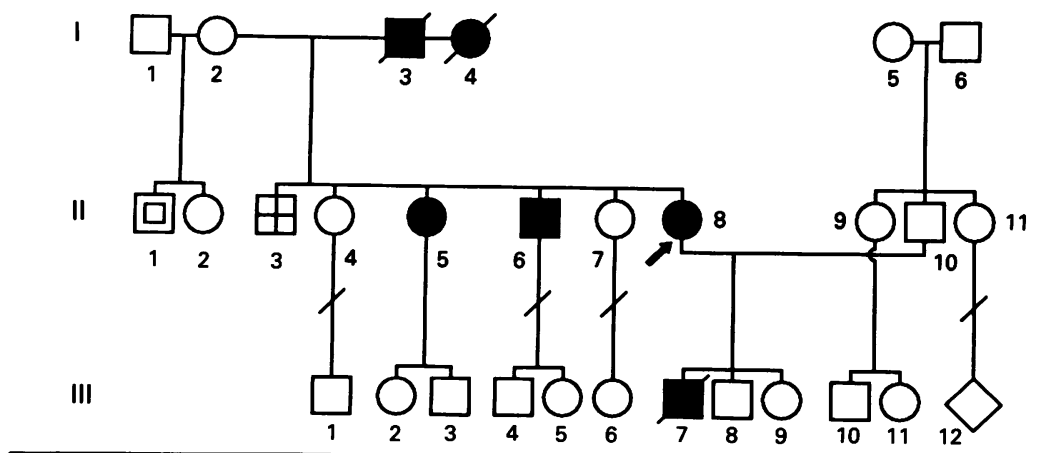

$$
\begin{aligned}
\square & =\text { ED affected } \\
\square & =\text { Mental retardation } \\
\boxplus & =\text { Deafness }
\end{aligned}
$$

Figure 1 The family pedigree. her hands and the distal radius and ulna. Approximately 20 to 30 fractures occurred after moderate trauma. Her susceptibility to fractures also prevented her from participating in sports.

Her skin was lax, velvety, and easily stretched. She had paper thin scars, particularly in the pretibial region. Her skin healed slowly after even minor trauma. Throughout her life she bruised easily and for prolonged periods. After the birth of each of her children, she developed post partum haemorrhage requiring dilatation and curettage of the uterus.

Her sight and hearing were normal. She had recurrent chest infections as a child and asthma for which she received intermittent antibiotics and bronchodilators.

At the age of 29 years she developed, over a period of 48 hours, respiratory symptoms and progressive weakness in her arms and legs and retention of urine. A diagnosis of transverse myelitis, probably unrelated to her EDS, was made. Her condition improved gradually over the next two years.

She was reviewed at the age of 32 years. Her facial appearance showed mild depression of the nasal bridge with prominent paranasal folds (fig 2). She continued to have stretchable, fragile skin (fig 3). She was confined to a wheel chair because of weakness of her arms and legs that resulted from a spinal cord lesion at the C5 level. In the presence of these neurological problems her generalised joint hypermobility became less troublesome. Shoulder movements were full, but there was marked laxity of the shoulders with excessive anteroposterior translation and a groove beneath the acromian indicating inferior subluxation. The superior radioulnar joints were subluxed. Her finger joints were lax (fig 4) and she was able to

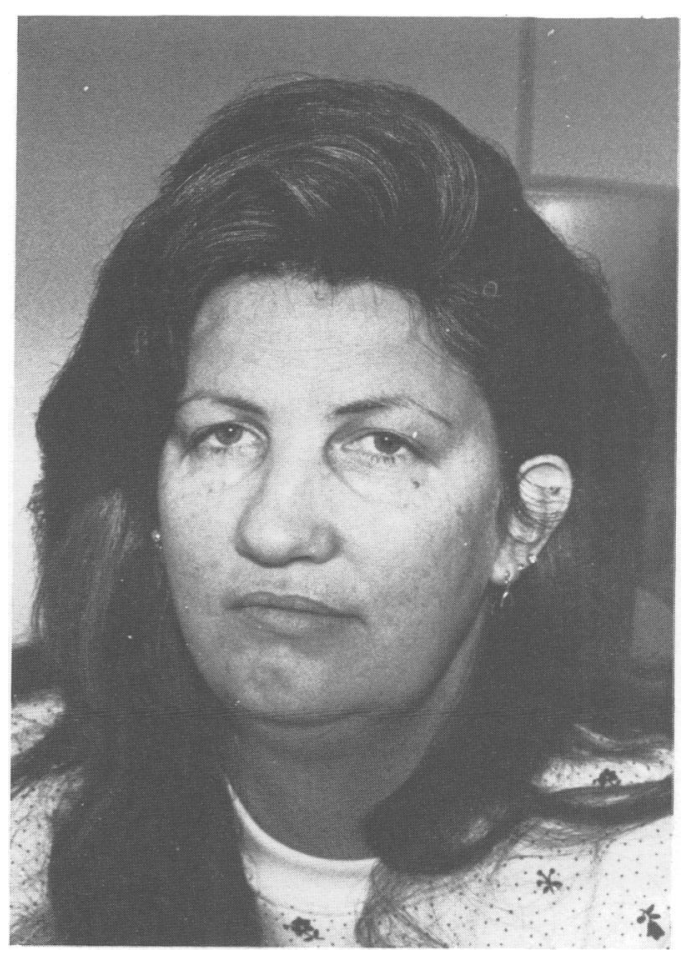

Figure 2 Facies of the proband showing a depressed nasal bridge with slightly prominent paranasal folds. 


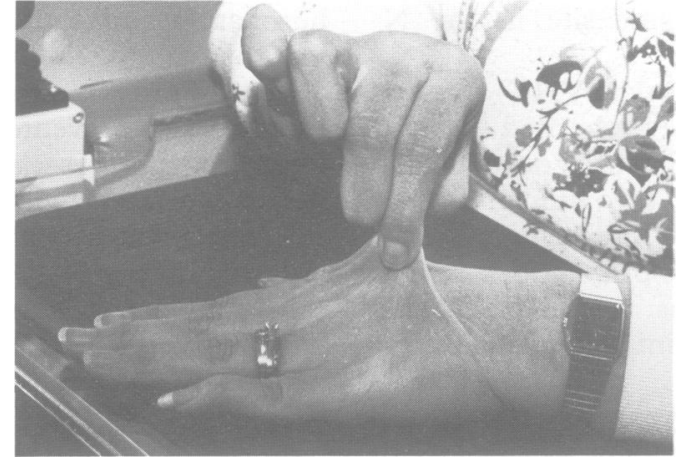

Figure 3 Appearance of the skin on the dorsum of the proband's hands showing hyperelasticity.

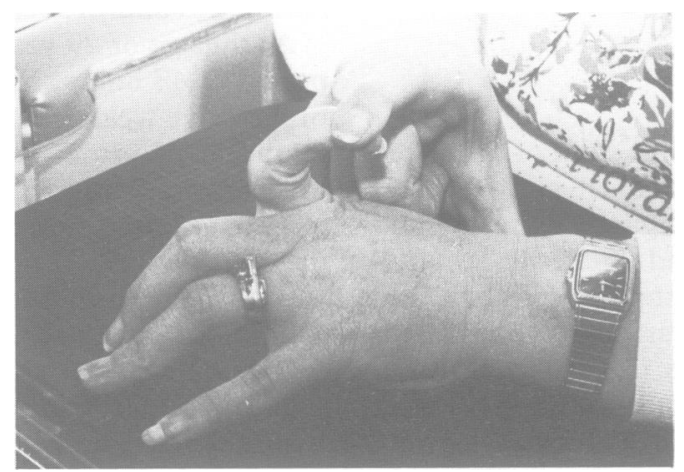

Figure 4 Appearance of the proband's fingers showing marked laxity of the interphalangeal joints which could be manipulated into marked hyperextension.

voluntarily produce swan neck deformities of her fingers (fig 5). Her hip movements were restricted in flexion and rotation while her knees flexed fully but hyperextended $20^{\circ}$. The patellofemoral joints were excessively lax and she was apprehensive about lateral movements of her patellae. She had plano-abducto-valgus deformities of the feet (fig 6).

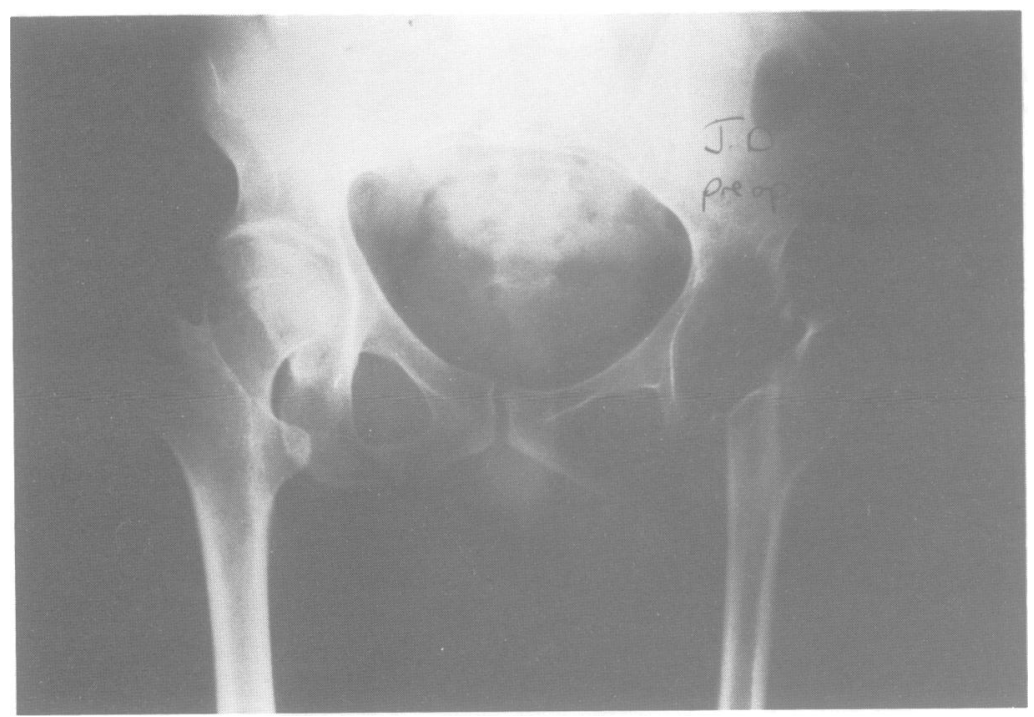

Figure 7 Anteroposterior radiograph of the pelvis of the proband's affected brother showing a dislocation of the hip with gross deformity of the proximal femur and narrowing of the joint space. A proximal femoral osteotomy had been performed in childhood.

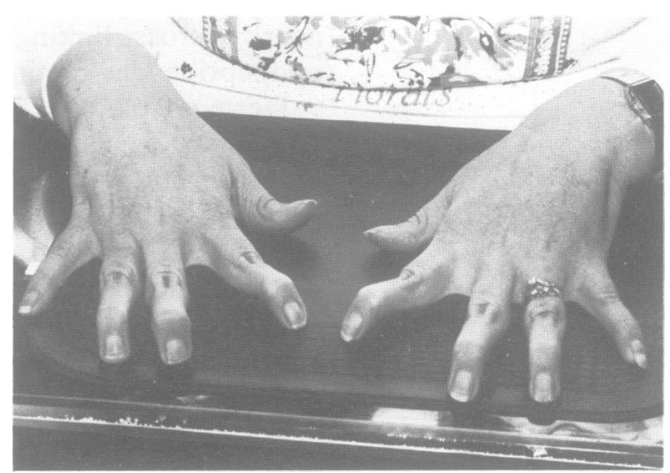

Figure 5 Appearance of the proband's hands showing swan neck deformities of the fingers.

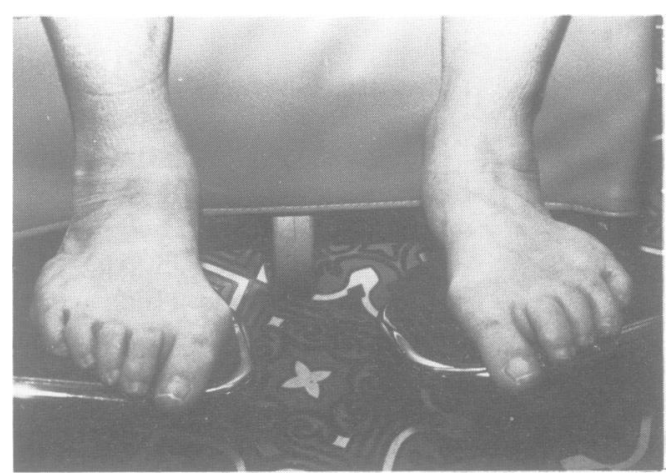

Figure 6 Appearance of the proband's feet showing plano-abducto-valgus deformities.

\section{FAMILY HISTORY}

The family pedigree showed affected members in three generations consistent with autosomal dominant inheritance of the syndrome (fig 1). The proband's affected father was also born with bilateral hip dislocations. He had marked joint hypermobility with intermittent patellar, interphalangeal, wrist, and shoulder dislocations and subluxations throughout his life. He bruised easily and produced poor, thin scars after trauma.

The proband had two affected sibs with similar clinical phenotypes. The female sib also sustained multiple fractures in childhood, mainly of the small bones of the hand, but also of the distal radius and olecranon.

The affected male sib was reviewed at 35 years of age when he underwent a total hip joint replacement. He was born with bilateral hip dislocations which required open surgical reductions in the first few years. One hip became osteoarthritic (fig 7) and was replaced at the age of 35 years. He was also disabled by the marked swan neck deformities of his hands and underwent reconstructive surgery in an attempt to reduce the deformities (fig 8). $\mathrm{He}$ was of normal height. He had easy bruising, skin hyperelasticity, and multiple fractures of the metacarpals, the distal radius, and distal ulna. He also sustained a fracture of the patella and olecranon. The frequency of fractures reduced markedly after his teenage years. His nasal bridge was mildly depressed and he had mild paranasal folds (fig 9).

The proband had three children of whom only the first was affected by the syndrome. He 


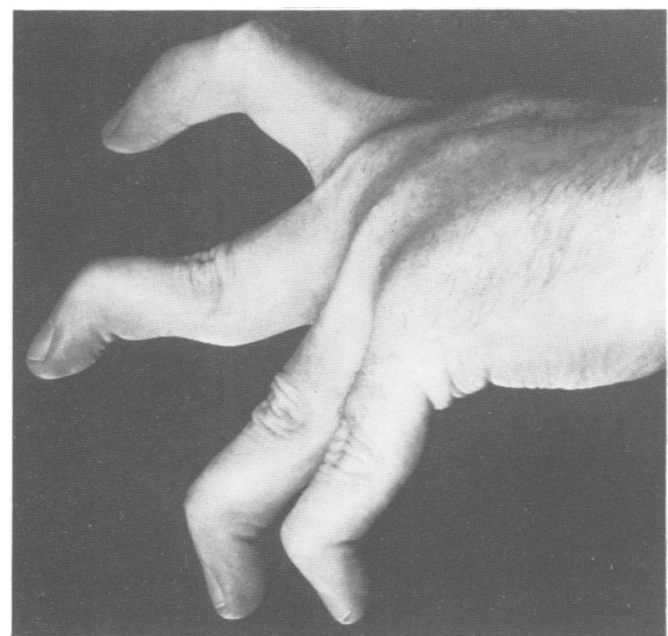

Figure 8 Appearance of the fingers of the proband's brother showing swan neck deformities.

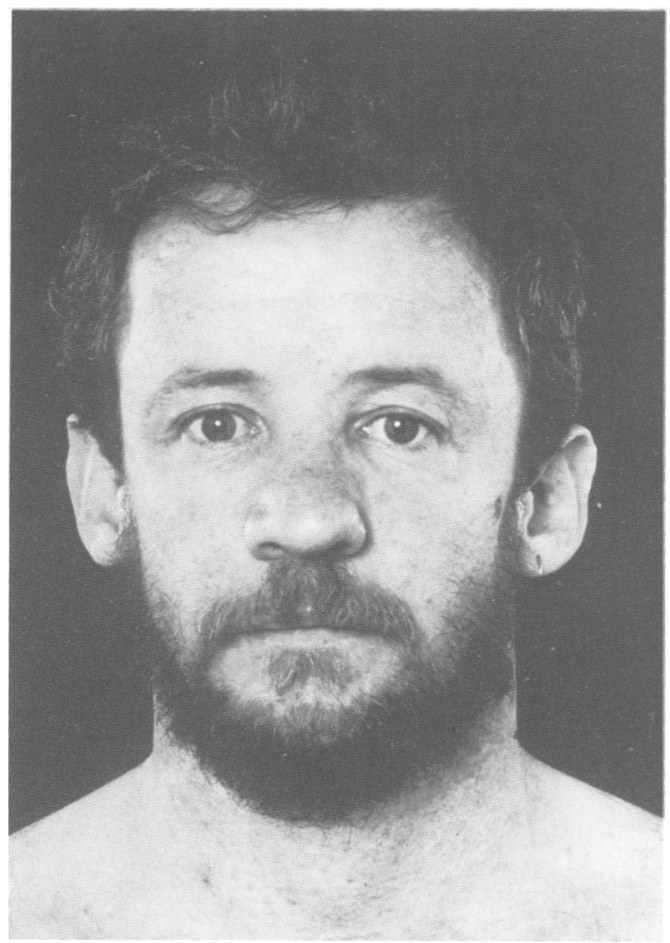

Figure 9 Facies of the proband's brother showing a depressed nasal bridge and slightly prominent paranasal folds.

was born by vaginal delivery at 36 weeks' gestation after premature rupture of membranes. He had bilateral hip and knee dislocations and generalised joint hypermobility. His hip dislocations were treated with plaster of Paris spica casts. An umbilical hernia was present at birth. He died suddenly at 2.5 months of age. Necropsy showed hugely dilated large intestine proximal to a kink of the sigmoid colon at the level of the pelvic brim. This was the only abnormality found to account for his death.

\section{PATHOLOGICAL FEATURES}

Specimens of skin from the proband, skin, deep fascia, and joint capsule from her affected brother, and similar tissue from a control were fixed in $2.5 \%$ gluteraldehyde, postfixed in osmium tetroxide, and embedded in Spurr's resin. Thin sections were stained with uranyl acetate, lead acetate, and tannic acid.

Electron microscopy showed that the proband's dermal collagen fibrils were round with only mild surface irregularities in transverse section (fig 10A,C), much less than the irregularities observed in a case of Ehlers-Danlos syndrome type VIIA (fig 10D). ${ }^{23}$ The affected and control specimens from the joint capsule and deep fascia showed some areas with a single population of fibrils and other areas with two populations of fibrils (fig 11A,B). The transverse sections did not show significant irregularity of the margins of the fibrils in either area.

In the proband's son who died at 2.5 months of age, the sigmoid colon was kinked with proximal dilatation of the colon. Light microscopic sections from the thoracic and abdominal viscera and a vertebra did not show any anomaly of the connective tissues. Re-processing of the paraffin embedded pericardium for transmission electron microscopy showed that collagen fibrils, in transverse section, had mainly smooth rounded outlines (fig 10B).

Light microscopy of bone from the femoral head of the proband's brother showed normal lamellar bone and well formed Haversian systems.

\section{BIOCHEMICAL FEATURES}

From the proband's affected brother, bone and fascial collagens were prepared using previously described methods and shown to contain approximately equal amounts of normal $\alpha 2(\mathrm{I})$ and mutant $\mathrm{pN} \alpha 2(\mathrm{I})$ chains (fig 12). ${ }^{2}$

Previous studies showed that the DNA extracted from formalin fixed and paraffin embedded samples of spleen and decalcified bone from the proband's affected son contained the same mutation. ${ }^{14}$

\section{Discussion}

The proband and her affected relatives had the clinical features of Ehlers-Danlos syndrome type VIIB with stretchable, fragile skin and gross joint hypermobility with multiple dislocations that were obvious at birth. These features as well as the electron microscopic finding of mainly rounded collagen fibrils were similar to those reported in other cases of EDS type VIIB. A major difference, however, was the high frequency of fractures in affected members of the current family. Transverse myelitis in the proband has not previously been reported in EDS. Its aetiology was not determined but it was probably unrelated to EDS as the onset and progress of the illness were typical of transverse myelitis.

The findings of approximately equal amounts of normal and mutant $\alpha 2(\mathrm{I})$ chains in the dermis, deep fascia, joint capsule, and bone suggests that all type I collagen containing tissues had a similar composition. This proposal is supported by similar observations in 

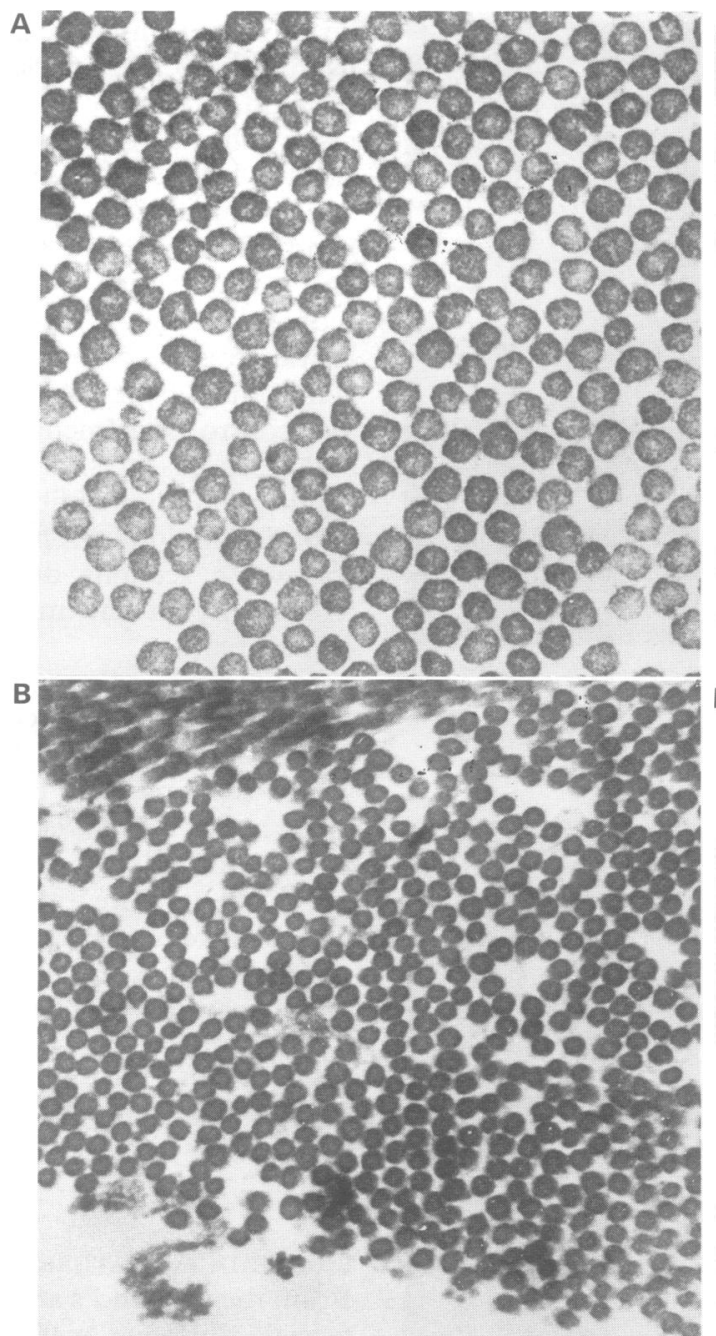

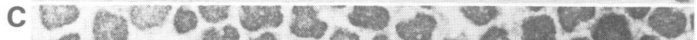

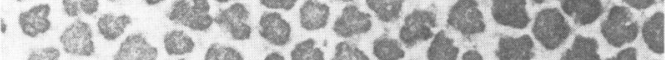

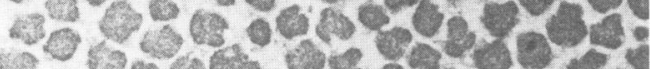

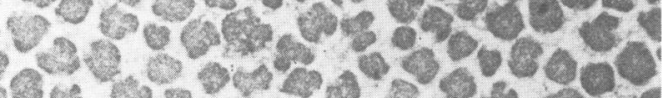

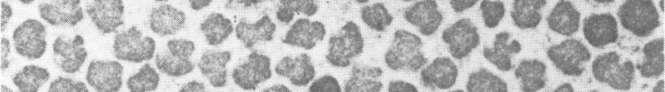

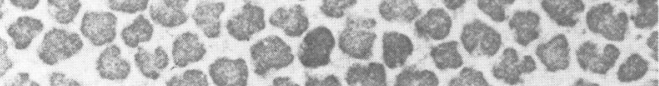

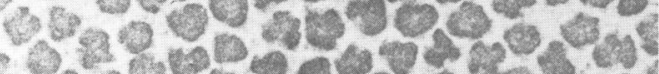

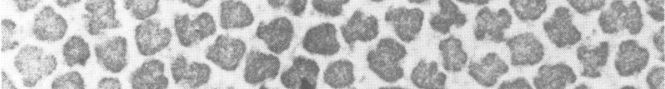

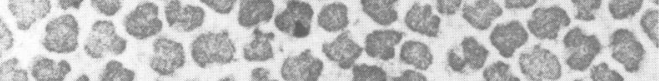
bes.

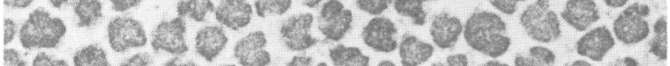

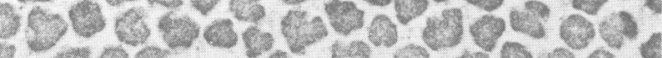

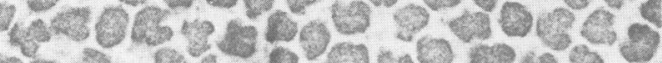

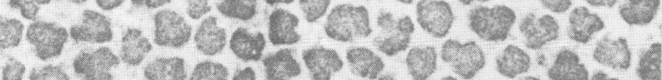

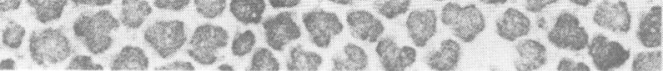
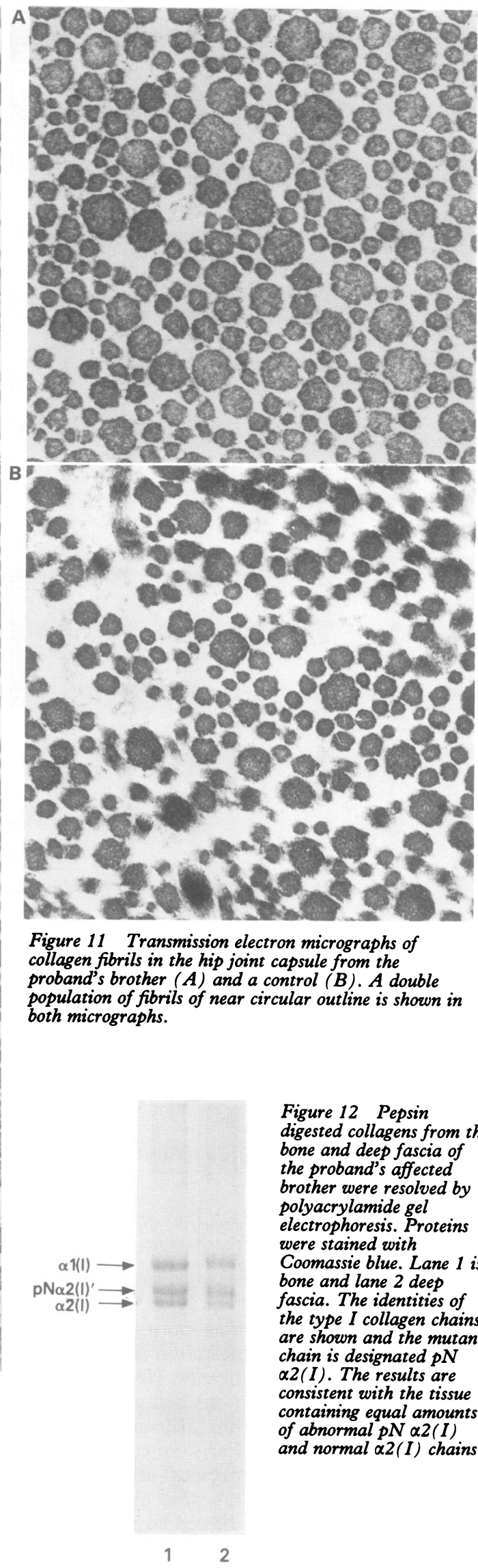

Figure 11 Transmission electron micrographs of collagen fibrils in the hip joint capsule from the proband's brother $(A)$ and a control $(B)$. A double population of fibrils of near circular outline is shown in both micrographs.

Figure 12 Pepsin

digested collagens from the bone and deep fascia of the proband's affected brother were resolved by polyacrylamide gel electrophoresis. Proteins were stained with

Coomassie blue. Lane 1 is

bone and lane 2 deep

fascia. The identities of

the type I collagen chains are shown and the mutant chain is designated $p N$

$\alpha 2(I)$. The results are

consistent with the tissue containing equal amounts of abnormal pN $\alpha 2(I)$ collagen fibrils in the dermis of the proband $(A)$, affected brother $(C)$. The fibrils from affected persons with EDS type VIIB are nearly circular in cross

section. They are more irregular than the control fibrils but less irregular than the fibrils of a case of $E D S$ and normal $\alpha 2(I)$ chains. 
another case of EDS type VIIB. ${ }^{24}$ The abnormal biochemical composition and mildly irregular collagen fibrils of the dermis and joint capsule provide an explanation for the skin and joint abnormalities observed in EDS type VIIB. The abnormal collagen composition of the bone also provides an explanation for the bone fragility that was a feature of affected members of the present family. However, the bone, in keeping with the dermis, fascia, and joint capsule, did not show any light microscopic changes in the extracellular matrix. Similarly, no abnormalities in trabecular architecture or density of the bone were evident from standard radiographs.

The bone fragility observed in the present family may reflect the uniqueness of the mutation which resulted in the loss of the Nproteinase cleavage site and retention of the nearby lysine cross linking site in the $\mathrm{N}$ telopeptide of the $\alpha 2$ (I) chains. ${ }^{14}$ Alternatively, bone fragility may have been overlooked in other reported cases of EDS type VIIB. In support of the latter proposal, a further review of a previously reported case of EDS type VIIA showed that the child had sustained numerous fractures from minor injuries. ${ }^{23}$

The similar clinical and histological features of the reported cases and the current case of EDS VIIB suggest that the loss of the Nproteinase cleavage site with retention of the $\mathrm{N}$-propeptide is of greater importance in the pathogenesis of the disorder than the loss of the cross linking lysine residue in the $\mathrm{N}$ telopeptide of the $\alpha 2(\mathrm{I})$ chain. This proposal is supported by the features of EDS type VIIC (dermatosparaxis) in which a deficiency of $\mathrm{N}$ proteinase activity results in the retention of the $\mathrm{N}$-propeptides without loss of the cross linking lysine sites in the N-telopeptides. ${ }^{15} 2122$ Affected persons showed severe laxity and fragility of the skin, inguinal herniae, blue sclerae, micrognathia, and growth retardation. ${ }^{22}$ The collagen fibrils show hieroglyphic forms in cross section which probably result from the adverse effect of the persistent $\mathrm{pN}$ $\alpha 2(\mathrm{I})$ and $\mathrm{pN} \alpha 1(\mathrm{I})$ chains on collagen fibrillogenesis. $^{7}$

The features of the current family indicate an overlap between EDS type VII and osteogenesis imperfecta. In the latter disorder, bone fragility is the main clinical feature but ligament laxity is also frequent and may be severe, so producing mixed osteogenesis imperfecta and EDS phenotypes. ${ }^{825} 26$ In such cases, mutations involving the triple helical domain of type I collagen misalign the $\mathrm{N}$-proteinase cleavage sites and retard the processing of $\mathrm{pN}$ collagen to collagen. ${ }^{82526}$

This work was undertaken with grants from the National Health and Medical Research Council of Australia, The Royal Children's Hospital Research Foundation (Melbourne), and The Hospital for Sick Children (Toronto). A J Carr was a recipient of a Service Award from the Oxford Regional Health Board.

1 Beighton P, DePaepe A, Danks D, et al. International nosology of heritable disorders of connective tissue, Berlin 1986. Am $\mathcal{F}$ Med Genet 1988;29:581-94.

2 Cole WG, Chan D, Chambers DW, Walker ID, Bateman

JF. Deletion of 24 amino acids from the proal(I) gene of type I procollagen in a patient with the Ehlers Danlos syndrome type VII. f Biol Chem 1986;261:5496-503.

3 D'Alessio M, Bernard M, Pretorius PJ, De Wet $W$, Ramirez F. Complete nucleotide sequence of the region encompassing the first twenty-five exons of the human pro-alpha1(I) collagen gene (COL1A1). Gene
pals pro-alphal(I)

4 Weil D, D'Alessio M, Ramirez F, et al. A base substitution in the exon of a collagen gene causes alternative splicing and generates a structurally abnormal polypeptide in patient with Ehlers-Danlos syndrome type VII. EMBO $\mathcal{F}$ 1989;8:1705-10.

5 Weil D, D'Alessio M, Ramirez F, et al. Temperaturedependent expression of a collagen splicing defect in the fibroblasts of a patient with Ehlers-Danlos syndrome type VII. F Biol Chem 1989;264:16804-9.

6 Steinmann B, Tuderman L, Peltonen L, Martin GR McKusick VA, Prockop DJ. Evidence for a structura mutation of procollagen type $I$ in a patient with the Ehlers-Danlos syndrome type VII. $f$ Biol Chem 1980;255:8887-93.

7 Watson RB, Wallis GA, Holmes DF, Viljoen D, Byers PH, Kadler KE. Ehlers-Danlos syndrome type VII B: incomplete cleavage of abnormal type I procollagen by $\mathrm{N}$ proteinase in vitro results in the formation of copolymers of collagen and partially-cleaved pN collagen that are near of collagen and partially-cleaved pN collagen that are near

8 Minor RR, Sippola-Thiele M, McKeon J, Berger J, Prockop DJ. Defects in the processing of procollagen to collagen are demonstrable in cultured fibroblasts from patients with the Ehlers Danlos and osteogenesis imperfecta syndromes. $\mathcal{F}$ Biol Chem 1986;261:10006-14.

9 Nicholls AC, Oliver J, Renouf DV, McPheat J, Palan A Pope FM. Ehlers-Danlos syndrome type VII: a single base change that causes exon skipping in the type collagen $\alpha 2(\mathrm{I})$ chain. Hum Genet 1991;87:193-8.

10 Vasan NS, Kuivaniemi H, Vogel BE, et al. A mutation in the proa2(I) gene (COL1A2) for type I procollagen in Ehlers-Danlos syndrome type VII: evidence suggesting that skipping of exon 6 in RNA splicing may be a common cause of the phenotype. Am $\mathcal{F}$ Hum Genet 1991;48:305-17.

11 Weil D, Bernard M, Combates N, et al. Identification of a mutation that causes exon skipping during collagen premRNA splicing in an Ehlers-Danlos syndrome variant. $\mathscr{f}$ Biol Chem 1988;263:8561-4.

12 Weil D, D'Allessio M, Ramirez F, Eyre DR. Structural and functional characterisation of a splicing mutation in the pro- $\alpha 2(\mathrm{I})$ collagen gene of an Ehlers-Danlos type VII B patient. F Biol Chem 1990;265:16007-11.

13 Wirtz MK, Glanville RW, Steinmann B, Rao V, Hollister DW. Ehlers-Danlos syndrome type VIIB. Deletion of 18 amino acids comprising the N-telopeptide region of a pro 2 (I) chain. $\mathcal{F}$ Biol Chem 1987;262:16376-85.

14 Chiodo AA, Hockey A, Cole WG. A base substitution at the splice acceptor site of intron 5 of the COL1A2 gene activates a cryptic splice site within exon 6 and generates abnormal type I procollagen in a patient with EhlersDanlos syndrome type VII. $\mathcal{f}$ Biol Chem 1992;267:63619.

15 Lenaers A, Ansay M, Nusgens BV, Lapiere CM. Collagen made of extended a-chains, procollagen, in genetically-
defective dermatosparaxic calves. Eur $\mathscr{\mathcal { f }}$ Biochem 1971;23:533-43.

16 Lichtenstein JR, Martin GR, Kohn LD. Defective conversion of procollagen to collagen in a form of Ehlers-Danlos syndrome. Science 1973;182:298-300.

17 Holbrook KA, Byers PH. Structural abnormalities in the dermal collagen and elastic matrix from the skin of patients with inherited connective tissue disorders. $f$ Invest Dermatol 1982;79(suppl):7-16.

18 Counts DF, Byers PH, Holbrook KA, Hegreberg GA Dermatospraxis in a Himalayan cat. I. Biochemical study of dermal collagen. $\mathcal{F}$ Invest Dermatol 1980;74:96-9.

19 Holbrook KA, Byers PH, Counts DF, Hegreberg GA. Dermatosparaxis in a Himalayan cat. II. Ultrastructural studies of dermal collagen. $\mathcal{F}$ Invest Dermatol 1980;74:100-4.

20 Fjolstad SM, Helle O. A hereditary dysplasia of collagen tissues in sheep. F Pathol 1974;112:183-8.

21 Nusgens BV, Verellen-Dumoulin C, Hermanns-Le T, et al. Evidence for a relationship between Ehlers Danlos type Evidence for a relationship between Ehlers Danlos type
VII $\mathrm{C}$ in humans and bovine dermatosparaxis. Nature Genet 1992;1:214-7.

22 Smith LT, Wertelecki $W$, Milstone LM, et al. Human dermatospraxis: a form of Ehlers-Danlos syndrome that results from failure to remove the amino-terminal propeptide of type I procollagen. Am $\mathcal{f}$ Hum Genet 1992;51:235-44.

23 Cole WG, Evans R, Sillence DO. The clinical features of Ehlers-Danlos syndrome type VII due to a deletion of 24 amino acids from the proa(I) chain of type I procollagen. f Med Genet 1987;24:698-701.

24 Eyre DR, Shapiro FD, Aldridge JF. A heterozygous collagen defect in a variant of the Ehlers Danlos syndrome type VII. Evidence for a deletion in the pro 2 (I) chain. $f$ Biol Chem 1985;260:11322-9.

25 Byers PH, Shapiro JR, Rowe DW, David KE, Holbrook KA. Abnormal $\alpha 2$-chain in type I collagen from a patient with a form of osteogenesis imperfecta. $f$ Clin Invest with a form of

26 Sippola M, Kaffe S, Prockop DJ. A heterozygous defect for structurally altered'pro- $\alpha 2$ chain of type I procollagen in a mild variant of osteogenesis imperfecta. $\mathcal{f}$ Biol Chem 1984;259:14094-100. 